\title{
Clinical Study Regardingthe Significance of Doppler \& Modified Biophysical Profile in the Management of Post Dated Pregnancy
}

\author{
Dr. R.K. Talukdar ${ }^{1}$, Dr. Nabanita Deka ${ }^{2}$, Dr. Moohibul Rahman ${ }^{3 *}$ \\ ${ }^{1}$ Professor \& HOD, Department of Obstetrics \& Gynaecology, Gauhati Medical College and Hospital Guwahati, Assam, India \\ ${ }^{2}$ Asst. Professor, Department of Obstetrics \& Gynaecology, Gauhati Medical College and Hospital, Guwahati, Assam, India \\ ${ }^{3}$ Post Graduate Trainee, Department of Obstetrics \& Gynaecology, Gauhati Medical College and Hospital, Guwahati, Assam, India
}

DOI: $\underline{10.36348 / \text { sijog.2019.v02i11.005 }}$

| Received: 10.11.2019 | Accepted: 16.11.2019 | Published: 20.11.2019

*Corresponding author: Dr. Moohibul Rahman

Abstract

Background: Prolonged gestation complicates 5\% to $10 \%$ of all pregnancies and confers increased risk to both the fetus and mother. In the west about $18 \%$ of all singleton pregnancies persist $>41$ weeks, $10 \%,>42$ weeks and $4 \%$ (range, $2 \%$ to $7 \%$ ) > 43 weeks without any obstetric intervention. The risks for prolonged and post-term pregnancy include obesity, nulliparity, maternal age $>30$ years. Racial and ethnic differences have also been cited to be the reasons for higher risk of prolonged and post-term pregnancy. Methods: A prospective study was carried out at Department of Obstetrics and Gynaecology, Gauhati Medical College \& Hospital, Guwahati, Assam. 300 patients were selected and divided into three groups and were followed up with Doppler and MBPP till the delivery. Data so collected was subjected to Statistical analysis. Results: Majority of women enrolled in the study were aged around 25 years, multigravida (58\%) and the study and control groups were matched demographically. The Doppler \& modified biophysical profile was recorded in study and control group. Rate of caesarean delivery in spontaneous \& induced, Baby NICU admission \&mortality. Conclusions: This study had showed that its use can predict adverse perinatal outcome in low risk pregnancy in prediction of asphyxia. Hence our study recommends use of combimed Cerebroplacental ratio \& MBPP has better sensitivity in postdated pregnancy to predict adverse perinatal outcome.

Keywords: Amniotic fluid index, Doppler umbilical and middle cerebral artery Modified biophysical profile, NST and post term pregnancy, post dated pregnancy

Copyright @ 2019: This is an open-access article distributed under the terms of the Creative Commons Attribution license which permits unrestricted use, distribution, and reproduction in any medium for non-commercial use (NonCommercial, or CC-BY-NC) provided the original author and source are credited.

\section{INTRODUCTION}

Any pregnancy continuing more than 40 weeks or 280 days of gestation is known as postdated pregnancy. Pregnancy more than 42 weeks or more than 294 days is called post term pregnancy. Fernandos Arias [1] defined prolonged pregnancy as those pregnancies advancing beyond the expected date of delivery (EDD. Its incidence has been estimated to be between $4-14 \%$ with an average of $10.5 \%$.In the west about $18 \%$ of all singleton pregnancies persist beyond 41 weeks, $10 \%$ (range, $3 \%$ to 14\%) continue beyond 42 weeks and $4 \%$ (range, $2 \%$ to $7 \%$ ) continue beyond 43 completed weeks in the absence of an obstetric intervention. Apart from these racial and ethnic differences have also been cited to be the reasons for higher risk of prolonged and post-term pregnancy. Nearly, 5 to $10 \%$ of all pregnancies continue to at least
42 weeks gestation. Globaly In the absence of a national data base in India, the prevalence of pregnancies continuing 42 weeks or more has been reported to be ranging from $2 \%$ to $7.7 \%$. 'Post-mature pregnancy' or 'post-maturity syndrome', which specifically describe the effects of intrauterine growth deficiency secondary to placental insufficiency in the prolonged gestation. Yet hence its early and appropriate management is essential to ensure the maternal as well as perinatal wellbeing (fact that continued intra-uterine existence beyond forty-two weeks gestation is associated with a high incidence of placental insufficiency, fetal post-maturity (dysmaturity), and increased risk of perinatal death).

Gestational age estimation is most important for poatdated pregnancy diagnosis, based either on the 
history, physical examination or laboratory findings, may be needed. Ultrasonographic assessment of gestational age in the first trimester of pregnancy is more accurate than any other methods of diagnosis of gestational age.

In postdated pregnancy there is declination of placental function (increased placental apoptosis, placental aging, and placental degeneration). Post-term pregnancy is associated with oligohydramnios. AFI <5 and deepest pocket $<2$ are commonly considered for oligohydramnios.

Postdated pregnancies (>42wks) have been associated with increased perinatal morbidity and mortality. Increased incidence of induction of labour, instrumental delivery, caesarean section, shoulder dystocia, lower APGAR score, congenital malformations, meconium aspiration, and foetal asphyxia have been associated with these pregnancies

Post dated expectant management should be monitored with non-stress tests, amniotic fluid index, or biophysical profile. However, evidence of benefit is lacking. Common methods for fetal surveillance include fetal movement counting, non-stress test (NST), biophysical profile, modified biophysical profile (NST and amniotic fluid volume estimation) and contraction stress test. The fetal biophysical profile is one of the most widely accepted tests for the evaluation of fetal wellbeing in high risk cases.

MBPP suggested by Nageotte et al., [2] combines Non-stress test (NST) as a short term marker of fetal status and the amniotic fluid index (AFI) as a marker of long term placental function and is easier to perform and less time consuming than complete biophysical profile,. Despite its usefulness in assessment of perinatal risk and as a tool of fetal surveillance, there are limited studies on evaluation of Modified Biophysical Profile in management of post- dated pregnancies. The present study was proposed to fill these gaps.

\section{METHODS}

This was a prospective analytical case control study carried out in Department of OBG, Guwahati medical college \& hospital, Assam from June 2018 to may 2019. Pregnant women of the study population who had completed 40 weeks and term (>37wks) of pregnancy were included. Pregnant women with obstetrical, surgical or medical complications contraindicated for vaginal delivery were excluded from the study. 300 patients were selected and 150 patients (>40wks) were assigned into two groups. All study pregnant women whom fetal surveillance was carried out using UA \& MCA Doppler and Modified Biophysical Profile criteria and Controls $(n=150)$, induced for labour in indicated cases $>37$ th week of pregnancy NST and AFI assessment twice a week or more frequently in case of decreased DFMC > 37 weeks of gestational age emergency LSCS was done if there was ominous NST. Progress of labour was monitored for all the cases irrespective of spontaneous / induction or LSCS decisions. All the women were followed up till the outcome of pregnancy. Following outcome were measured incidence of spontaneous onset of labour between 37-40 weeks, feto-maternal surveillance of $>37$ weeks and emergency LSCS forominous NST. Change in AFI in groups Time \& mode of delivery in $>40$ wks. Data so collected was subjected to analysis using Statistical

\section{RESULTS AND OBSERVATIONS}

The study "Clinical Study Regarding The Significance Of Doppler \& Modified Biophysical Profile In The Management Of Post Dated Pregnancy" is conducted in the department of Obstetrics and Gynaecology of Gauhati Medical College and Hospital from June, 2018 to May 2019. The results and observation are shown below.

Table-1: Distribution of cases

\begin{tabular}{|l|l|l|l|c|}
\hline \multirow{2}{*}{} & \multicolumn{2}{|c|}{ Study Group } & Control group (gestational & Total \\
\cline { 2 - 3 } & $\begin{array}{l}\text { Group1a(gestational age 40- } \\
\text { alweeks) }\end{array}$ & $\begin{array}{l}\text { Group1b(gestational age- } \\
\text { 41 weeks onwards }\end{array}$ & 300 \\
\hline No Of Cases & $97(32.3 \%)$ & $53(17.7 \%)$ & $150(50 \%)$ & \\
\hline
\end{tabular}

As shown in Table-1 a total of 300 cases were selected for this study. The study group comprised of 150 women. This group is subdivided in two groups group 1A consisting of 97 women having gestational age of 40-41 weeks and group 1B consisting of 53 women having gestational age more than 41 weeks where as 150 women belonged to gestational age of 37 to 40 weeks taken as control group. 
R.K. Talukdar et al; Sch Int J Obstet Gynec, Nov. 2019; 2(11): 277-283

Table-2: Age Distribution

\begin{tabular}{|l|l|l|l|l|}
\hline \multirow{2}{*}{ AGE IN YEARS } & \multicolumn{2}{|l|}{ STUDY GROUP } & \multirow{2}{*}{ CONTROL } & P VALUE \\
\cline { 2 - 3 } \cline { 2 - 3 } & GROUP1A & GROUP1B & & \\
\hline 18- 24 YEARS & $31(31.9 \%)$ & $14(26.4 \%)$ & $46(30.7 \%)$ & \multirow{3}{*}{ 0.18 } \\
\hline 25-30YEARS & $59(60.8 \%)$ & $27(50.9 \%)$ & $74(49.3 \%)$ & \\
\hline 30-35YEARS & $7(7.2 \%)$ & $12(22.7)$ & $30(20 \%)$ & \\
\hline TOTAL & $100 \%$ & $100 \%$ & $100 \%$ & \\
\hline MEAN AGE & $25 \pm 3.8$ & $26 \pm 4.5$ & $25.3 \pm 4.6$ & \\
\hline
\end{tabular}

As shown in Table-2 mean age of $1 \mathrm{~A}, 1 \mathrm{~B}$ \&control group is 25, 26 years and 25 years. Most of the cases belong to age group of 25-29 years. $\mathrm{P}$ value is 0.18 which is statistically not significant.

Table-3: Parity distribution

\begin{tabular}{|l|l|l|l|}
\hline & PRIMIGRAVIDA & MULTIGRAVIDA & P VALUE \\
\hline GROUP1A & $53(54.6 \%)$ & $44(45.3 \%)$ & \multirow{2}{*}{0.08} \\
\hline GROUP1B & $18(33.96 \%)$ & $35(66.03 \%)$ & \\
\hline CONTROL & $55(36.7 \%)$ & $95(63.3 \%)$ & \\
\hline
\end{tabular}

As shown in Table-3 primigravida in $1 \mathrm{~A}, 1 \mathrm{~B}$ \& control group is $54.6 \%, 33.96 \% \& 36.7 \%$ and multigravida.is $45.3 \%, 66.03 \%$ \& $63.3 \%$ respectively. $\mathrm{P}$ value is 0.08 hence no significant statistical association between parity and postdated pregnancy.

Table-4: Largest pocket diameter measurement

\begin{tabular}{|l|l|l|l|l|}
\hline & GROUP1A & GROUP1B & CONTROL & P VALUE \\
\hline LPD & 3 & 2.3 & 3.8 & $<0.0001$ \\
\hline
\end{tabular}

As shown in Table-4 the mean of largest pocket diameter is $3 \mathrm{~cm}, 2.3 \mathrm{~cm} \& 3.8 \mathrm{~cm}$ in group $1 \mathrm{~A}$, 1B \& control. P value is $<0.0001$ which is statistically significant. Hence, decrease in liquor volume in postdated pregnancy beyond 41 weeks.

Table-5: Mode of delivery

\begin{tabular}{|l|l|l|l|}
\hline & VD & LSCS & P VALUE \\
\hline GROUP1A & $71(73.2 \%)$ & $26(26.8 \%)$ & \multirow{2}{*}{0.0001} \\
GROUP1B & $34(64.2 \%)$ & $19(35.8 \%)$ & \\
\hline CONTROL & $127(86.7 \%)$ & $23(15.3 \%)$ & \\
\hline
\end{tabular}

As shown in Table-5 in 1A, 1B \& control group delivered by VD in $73.2 \%, 64.2 \& 86.7 \%$ and by LSCS in $26.8 \%, 35.8 \& 15.3$ of cases. Highest percentage of LSCS is seen in group1B $\mathrm{P}$ value is 0.0001 which is statistically significant.

Table-6: Induction and outcome

\begin{tabular}{|l|l|l|l|l|l|}
\hline \multirow{2}{*}{} & \multicolumn{2}{|l|}{ INDUCTION OF LABOUR } & \multicolumn{2}{l|}{ SPONTANEOUS ONSET OF LABOUR } & \multirow{2}{*}{ P VALUE } \\
\cline { 2 - 5 } & VD & LSCS & VD & LSCS & \multirow{2}{*}{$\mathbf{0 . 0 0 0 1}$} \\
\hline GROUP1A & $40(74 \%)$ & $14(26 \%)$ & $31(65.1 \%)$ & $12(34.9 \%)$ & \\
\hline GROUP1B & $12(60 \%)$ & $8(40 \%)$ & $22(60.6 \%)$ & $11(39.4 \%)$ & $9(9.1 \%)$ \\
\hline CONTROL & $40(78.4 \%)$ & $11(21.6 \%)$ & $90(90.9 \%)$ & & \\
\hline
\end{tabular}

As shown in Table-6 VD following induction in $1 \mathrm{~A}, 1 \mathrm{~B}$ and control group are $74 \%, 60 \%$ and $78.4 \%$ spontaneous vaginal delivery rate are $65.1 \%, 60.6 \%$ and
90.9\% respectively. LSCS following induction is seen to be high in group1 A and group1B. $\mathrm{P}$ value is <.0001 which is statistically significant.

Table-7: NICU admission in group1A, $1 B$ and control group

\begin{tabular}{|l|l|l|l|}
\hline & NICU ADMISSION & \multirow{2}{*}{ P VALUE } \\
\cline { 1 - 2 } & YES & NO & \multirow{2}{*}{0.001} \\
\hline GROUP1A & $34(35.05 \%)$ & $63(64.94 \%)$ & \\
\cline { 1 - 2 } CONTROL & $23(43.3 \%)$ & $30(56.7 \%)$ & \\
\hline
\end{tabular}


R.K. Talukdar et al; Sch Int J Obstet Gynec, Nov. 2019; 2(11): 277-283

As shown in Table-7 NICU admission in group 1A, 1B and control is $35.05 \%, 43.3 \%$ \& $20 \%$. The neonatal admission rate is maximum in gruoup1B which is $43.3 \%$ followed by group $1 \mathrm{~A} 35.05 \%$. $\mathrm{P}$ value is 0.001 whice is statasticaly significant.

Table-8: Perinatal mortality) in group1A, 1B \& control

\begin{tabular}{|c|c|c|c|}
\hline & \multicolumn{2}{|c|}{ PERINATAL MORTALITY } & P VALUE \\
\hline & YES & NO & \\
\hline GROUP1A & $11(11.34 \%)$ & $86(88.65 \%)$ & \\
\hline GROUP1B & $2(3.7 \%)$ & $51(96.3 \%)$ & 0.002 \\
\hline CONTROL & $5(3 \%)$ & $145(97 \%)$ & \\
\hline
\end{tabular}

As shown in Table- 8 Perinatal mortality rate in group 1A, 1B and control are 11.34\%, 3.7\% and 3\% respectively. $\mathrm{P}$ value is $<0.05$ which is statistically significant.

Table-9: Doppler Resistance Index among study and control group

\begin{tabular}{|l|l|l|l|}
\hline \multirow{2}{*}{} & \multicolumn{2}{|c|}{ MEAN \pm SD } & P VALUE \\
\cline { 2 - 4 } & STUDY GROUP & CONTROL GROUP & \\
\hline MCA RI & $0.67 \pm 0.18$ & $0.72 \pm 0.27$ & 0.008 \\
\hline UA RI & $0.71 \pm 0.30$ & $0.66 \pm 0.14$ & $>0.5$ \\
\hline MCARI/UA RI & $1.0 \pm 0.2$ & $1.1 \pm 0.25$ & $<0.001$ \\
\hline
\end{tabular}

As shown Table-9 MCA RI/UA RI \& MCA RI is low in study group than control group. P value being $0.001 \&$ 0.0008 Both are statistically significant.

Table-10: Doppler Pulsatility Index among study and control group

\begin{tabular}{|l|l|l|l|}
\hline \multirow{2}{*}{} & \multicolumn{2}{|c|}{ MEAN \pm SD } & \multirow{2}{*}{ P VALUE } \\
\cline { 2 - 3 } & STUDY GROUP & CONTROL GROUP & \\
\hline MCA PI & $1.6 \pm 0.55$ & $1.2 \pm 0.34$ & $<0.0001$ \\
\hline UA PI & $1.24 \pm 0.43$ & $1.07 \pm 0.96$ & $<0.64$ \\
\hline MCA PI/UA PI & $1.32 \pm 0.30$ & $1.66 \pm 1.39$ & 0.0012 \\
\hline
\end{tabular}

As shown in Table-10 value of MCA PI is seen to be more in study group. $\mathrm{P}$ value is less than $<0.03$ which shows statistically significant association.

Table-11: Co- relation of abnormal (MCA RI/UA RI) ratio and NICU admission in study group

\begin{tabular}{|l|l|l|l|}
\hline \multirow{2}{*}{ NICU ADMISSION } & \multicolumn{2}{|c|}{ MCA RI/UA RI } & \multirow{2}{*}{ P VALUE } \\
\cline { 2 - 3 } & NORMAL n=97 & ABNORMAL $\mathbf{n = 5 3}$ & \multirow{3}{*}{$<0.0001$} \\
\hline YES & $12(12.3 \%)$ & $36(60.3 \%)$ & \\
\hline NO & $85(87.7 \%)$ & $17(39.7 \%)$ & \\
\hline
\end{tabular}

As shown in Table-11 maximum number of than 0.85 which is $60 \%$. $\mathrm{P}$ value is 0.001 which is NICU admission is seen with MCA RI/UA RI ratio less statistically very significant.

Table-12: Co relation between abnormal CPR (MCA PI/UA PI) and NICU admission

\begin{tabular}{|l|l|l|l|}
\hline \multirow{2}{*}{ NICU ADMISSION } & \multicolumn{2}{|c|}{ MCA PI/UA PI } & \multirow{2}{*}{ P VALUE } \\
\cline { 2 - 3 } & NORMAL n=119 & ABNORMAL n=28 & \\
\hline YES & $33(27 \%)$ & $25(89.2 \%)$ & $<.0001$ \\
\hline NO & $86(73 \%)$ & $3(10.8 \%)$ & \\
\hline
\end{tabular}

As seen in Table-12 and abnormal CPR (MCAPI/UA PI) is seen in 18 cases and 16 of them were admitted in NICU. P value is $<0.0001$ which is statistically very significant. 
R.K. Talukdar et al; Sch Int J Obstet Gynec, Nov. 2019; 2(11): 277-283

Table-13: Comparison of Doppler Indices in relation to NICU admission in study group

\begin{tabular}{|l|l|l|l|}
\hline INDICES & NICU ADMITTED & NICU NOT ADMITTED & P VALUE \\
\hline MCA RI & $0.68 \pm 0.17$ & $0.67 \pm 0.18$ & 0.79 \\
\hline UA RI & $0.81 \pm 0.40$ & $0.65 \pm 0.21$ & 0.002 \\
\hline MCA PI & $1.55 \pm 0.57$ & $1.6 \pm 0.54$ & 0.16 \\
\hline UA PI & $1.3 \pm 0.50$ & $1.2 \pm 0.36$ & 0.008 \\
\hline MCA RI/UA RI & $0.91 \pm 0.20$ & $1.05 \pm 0.25$ & $<0.0006$ \\
\hline MCA PI/UA PI & $1.19 \pm 0.29$ & $1.36 \pm 0.35$ & $<.003$ \\
\hline
\end{tabular}

From Table-13 and it is seen that there is increased in UARI, UAPI, MCARI/UARI

\&MCAPI/UAPI in NICU admitted group than NICU non admitted group. $\mathrm{P}$ value is statistically significant.

Table-14: Co relation between abnormal CU (MCA RI/UA RI) and Perinatal outcome

\begin{tabular}{|l|l|l|l|}
\hline \multirow{2}{*}{ OUTCOME } & \multicolumn{2}{|c|}{ MCA RI/UA RI } & \multirow{2}{*}{ P VALUE } \\
\cline { 2 - 3 } & NORMAL n=97 & ABNORMAL n=53 & \\
\hline HEALTHY & $94(97 \%)$ & $44(83 \%)$ & .002 \\
\hline PERINATAL DEATH & $3(3 \%)$ & $9(17 \%)$ & \\
\hline
\end{tabular}

As shown in Table-14 it seen that perinatal death of abnormal \&normal MCA RI/UA RI ratio value is $17 \%$ \& $3 \%$ respectively. $\mathrm{P}$ value is 0.002 which is statistically significant.

Table-15: Co relation of abnormal CPR (MCA PI/UA PI) and perinatal outcome

\begin{tabular}{|l|l|l|l|}
\hline \multirow{2}{*}{ OUTCOME } & \multicolumn{2}{|c|}{ MCA PI/UA PI } & \multirow{2}{*}{ P VALUE } \\
\cline { 2 - 3 } & NORMAL n=119 & ABNORMAL n=28 & \\
\hline HEALTHY & $116(97.4 \%)$ & $19(67.9 \%)$ & $<0.0001$ \\
\hline PERINATAL DEATH & $3(2.6 \%)$ & $9(32.1 \%)$ & \\
\hline
\end{tabular}

As shown in Table-15 and perinatal death seen with abnormal \& normal MCA PI/UA PI ratio is $33 \%$
\& $2 \%$ respectively. $\mathrm{P}$ value is.0003 which is statistically significant.

Table-16: Assessment of Doppler indices with adverse perinatal outcome

\begin{tabular}{|l|l|l|l|l|l|}
\hline & SENSITIVITY & SPECIFICITY & PPV & NPV & ACCURACY \\
\hline MCA RI & 36 & 60 & 53 & 44 & 47 \\
\hline UA RI & 46 & 75 & 73 & 48 & 58 \\
\hline MCA RI/UA RI & 97 & 88 & 79 & 98 & 91 \\
\hline MCA PI & 75 & 63 & 7 & 98 & 63 \\
\hline UA PI & 40 & 71 & 81 & 27 & 48 \\
\hline MCA PI/UA PI & 89 & 73 & 42 & 97 & 76 \\
\hline
\end{tabular}

As shown in Table-16 MCA RI/UA RI has higher sensitivity $98 \%$, specificity $88 \%$, NPV $98 \%$, and PPV $79 \%$ is low. MCA PI/UA PI has high sensitivity
$89 \%$, specificity $73 \%$, and NPV $97 \%$ but low PPV $42 \%$.

Table-16: Assessment of modified Biophysical profile

\begin{tabular}{|l|l|l|l|l|}
\hline \multirow{2}{*}{ GROUPS } & \multicolumn{2}{|c|}{ NST } & \multirow{2}{*}{ Oligo } & \multirow{2}{*}{ P Value } \\
\cline { 2 - 4 } & Reactive & Non-reactive & & \\
\hline 1A & 76 & 12 & 9 & \multirow{2}{*}{$<0.0001$} \\
\hline 1B & 28 & 10 & 15 & \\
\hline Control & 143 & 4 & 3 & \\
\hline
\end{tabular}

As shown in Table-16 the NST nonreactive of group 1A, 1B and Control is 7, 11, and 4 respectively. $\mathrm{P}$ value is.0001 which is statistically significant. 
R.K. Talukdar et al; Sch Int J Obstet Gynec, Nov. 2019; 2(11): 277-283

\begin{tabular}{|l|c|c|c|l|l|l|l|}
\hline El-sokary & 2011 & 50 & 41 & $\begin{array}{l}\text { Low } \\
\text { risk }\end{array}$ & $\begin{array}{l}\text { Perinatal death,cs for fetal distress, admission in nicu } \\
\text {,days in nicu, low apgar }\end{array}$ & .98 & Predictive \\
\hline Antonio & 2013 & 320 & 41 & $\begin{array}{l}\text { Low } \\
\text { risk }\end{array}$ & $\begin{array}{l}\text { Neonatal acidosis, operative delivery for abnormal } \\
\text { intrapartumfetal ECG-ST segment analysis }\end{array}$ & 0.98 & $\begin{array}{l}\text { Not } \\
\text { predictive }\end{array}$ \\
\hline $\begin{array}{l}\text { Present } \\
\text { study }\end{array}$ & 2014 & 100 & 40 & $\begin{array}{l}\text { Low } \\
\text { risk }\end{array}$ & abnormal apgar, admission in nicu, perinatal mortality & 1.08 & Predictive \\
\hline
\end{tabular}

\section{DISCUSSION}

In this study mean of largest pocket diameter in group1 A is $3 \mathrm{~cm}$, in group $1 \mathrm{~B}$ is $2.3 \mathrm{~cm}$, in control group is $3.8 \mathrm{~cm}$. $\mathrm{P}$ value is 0.022 which shows statistically significant association between the groups.in our study the incidence of oligohyadramnios is found to be $20 \%$. J. M. Morrisa et al., [3] found incidence of $7.9 \%$ and Bahado Singh et al., [4] found a incidence of $14.3 \%$.

MCA RI in NICU admitted group is $0.68 \pm 0.17$, in NICU not admitted group it is $0.67 \pm 0.18$. Umbilical artery RI in NICU admitted group is $0.81 \pm 0.4$, in NICU not admitted group it is $0.65 \pm 0.21$. Our study value of UA RI is comparable to El Sokkary $\mathrm{M}$ et al., [5] $\mathrm{P}$ value is of UA RI is 0.002 which is statistically significant.

\section{Abnormal}

- $\quad$ Lscs for fetal distress \&vaginal delivery 5 and 21 of 26 abnormal Doppler cases

- $\quad$ Lscs for fetal distress \&vaginal delivery is 12 and 10 of 22 of NST NR cases

- $\quad$ Lscs for fetal distress \&vaginal delivery is 22 and 2 of 24 abnormal Doppler \&NST NR cases

The pulsatility index of middle cerebral and umbilical artery are comparable to the result of the Ambreen Naveed Haq et al., [6] the pulsatility index of middle cerebral artery in study group is 1.6 and 1.4 respectively. In control group it is 1.2 and 1.2 in our study and Ambreen Naved Haq et al., respectively.

\section{SUMMARY}

- Mean age of group1A is 25years, group1B is 26 years and in control group it is 25 years. Most of the cases in all the three groups belong to age group 25-29 years. $\mathrm{P}$ value is 0.2 which is statistically not significant. Hence it is seen that there is no statistically significant association between age and occurrence of postdated pregnancy.

- $\quad 54.6 \%$ cases are primigravida and $45.6 \%$ cases are multigravida in group1A, in group1B $33.96 \%$ cases are primigravida and $66.04 \%$ cases are multigravida. In control group In control group $36.7 \%$ cases are primigravida and $63.3 \%$ cases are multigravida. $P$ value is 0.08 which shows no significant statistical association between parity and postdated pregnancy.
- Mean of largest pocket diameter of amniotic fluid is minimum in group1B which is 2.3 $\mathrm{cm}$.in group 1A it is $3 \mathrm{~cm}$ and in control group it is $3.8 \mathrm{~cm}$. P value comes out to be .02 which is statistically significant. Hence it is seen that there is decrease in liquor volume in postdated pregnancy beyond 41 weeks. Incidence of oligohyadramnios in study group is found to be $16 \%$.

- Amongst the 150 cases in 74 cases labour is induced and in 76 cases induction is not given. Out of 74 cases $24(44.4 \%)$ cases of group1A delivered vaginally and in group $1 \mathrm{~B}-10$ cases $(40 \%)$ cases delivered vaginally. In non induction group vaginal delivery in group 1A, and group $1 \mathrm{~B}$ are $65.1 \%$ and $60.6 \%$. Percentage of caesarean section is high in non induction group $1 \mathrm{~B}$ which is $60 \%$.

- Highest percentage of NICU admission is seen with group1B $43.3 \%(n=13)$, in group1A it is $35.05 \%(\mathrm{n}=34)$ and in control group it is $20 \%$ $(\mathrm{n}=30)$.

- 49 number of cases has MCA RI/ UA RI value $<0.85$.out of which $35(60 \%)$ cases were admitted in NICU and 8 cases had early neonatal death $(16.3 \%)$. $\mathrm{P}$ value is 0.02 which shows significant association between MCA RI/UA RI ratio $<0.85$ and poor perinatal outcome.

- 27 numbers of cases had MCA PI/ UA PI< 1.08 out of which 25 cases $(92.5 \%)$ had NICU admission. Perinatal mortality rate is seen to be $37.0 \%(n=10)$. . P value is.0003 which is statistically significant.

- MCA RI/ UA RI had a higher specificity $98 \%$ for predicting adverse perinatal outcome than MCA RI or UA RI alone. Its diagnostic accuracy is $91 \%$.

CU ratio has a specifity for predicting adverse Perinatal outcome than MCA PI or UA alone. MCA PI /UA PI has diagnostic accuracy of 76\% and MCA RI/ UA RI it is $91 \%$. .In the present study, the MCA RI/UA RI ratio with cutoff value $=0.85$ was found to be the most sensitive parameter in the prediction of adverse prenatal outcome. Among 58 cases admitted in NICU, 33 of them had a ratio below $0.85(57 \%)$ and only 25 cases above $0.85(43 \%)$. The Cereboplacental ratio (MCA RI/UA RI) screening efficiency for detecting adverse Perinatal outcome was 97\% Sensitivity, 88\% Specificity, $79 \%$ Positive predictive value, $98 \%$ Negative predictive value compared with the results of 
the present study (MCA/UA) PI ratio showed a $89 \%$ sensitivity and $73 \%$ specificity and a $42 \% \mathrm{PPV}$ and $97 \%$ NPV

\section{CONCLUSION}

Doppler ultrasonography in obstetrics is very important in the management of modern obstetrics cases. Its use in high risk pregnancy has been previously well established and this present study had showed that its use can predict adverse perinatal outcome in low risk pregnancy also DOPPLER indicates does of umbilical artery and middle cerebral artery does not significantly or abruptly changes in postdated pregnancy. Cerebroplacental ratio has better sensitivity in prediction of asphyxia when compared to individual umbilical and middle cerebral resistance or pulsality index. Hence our study recommends use of MCA RI/UA RI and MCA PI/UA PI in postdated pregnancy to predict adverse perinatal outcome and to decide and time mode of delivery and timely neonatal care.

- Post-term pregnancy is associated with increased risk of both intrauterine and postnatal death.

- In post-term pregnancies, impedance to flow in the uterine arteries is normal.

- In post-term pregnancies with adverse outcomes, impedance to flow in the umbilical arteries may be increased or normal.

- In post-term pregnancies with adverse outcome, impedance to flow in the fetal middle cerebral arteries may be decreased.

\section{REFERENCES}

1. Arias, F., Bhide, A., Arulkumaran, S., Damania, K., \& Daftary, S. (2014). Arias' Practical Guide to High-Risk Pregnancy and Delivery. Imprint: Elsevier India.

2. Nageotte, M. P., Towers, C. V., Asrat, T., \& Freeman, R. K. (1994). Perinatal outcome with the modified biophysical profile. American journal of obstetrics and gynecology, 170(5), 1672-1676.

3. Morris, J. M., Thompson, K., Smithey, J., Gaffney, G., Cooke, I., Chamberlain, P., ... \& MacKenzie, I. Z. (2003). The usefulness of ultrasound assessment of amniotic fluid in predicting adverse outcome in prolonged pregnancy: a prospective blinded observational study. BJOG: An International Journal of Obstetrics \& Gynaecology, 110(11), 989-994.

4. Bahado-Singh, R. O., Akolekar, R., Mandal, R., Dong, E., Xia, J., Kruger, M., ... \& Nicolaides, K. (2012). Metabolomics and first-trimester prediction of early-onset preeclampsia. The journal of maternal-fetal \& neonatal medicine, 25(10), 1840-1847.

5. El-Sokkary, M., Omran, M., \& Ahmed, H. (2011). Ratio of middle cerebral artery/umbilical artery Doppler velocimetry and status of newborn in postterm pregnancy. J Am Sci, 7(4), 542-549.

6. Haq, A. N., Sher, Z., \& Naz, S. (2010). Hyperreactio luteinalis associated with pregnancy induced hypertension. J Coll Physicians Surg Pak, 20(2), 137-139. 